\title{
Development of flexible textile aluminium-air battery prototype
}

\author{
Aleksandrs Vališevskis ${ }^{1}$. Uǵis Briedis ${ }^{1} \cdot$ Miguel Carvalho $^{2}$ [ $\cdot$ Fernando Ferreira $^{2}$
}

Received: 2 March 2020 / Accepted: 18 January 2021 / Published online: 3 February 2021

(c) The Author(s) 2021

\begin{abstract}
There is one component that virtually any embedded wearable needs-a power source. This paper proposes an energy source, which contains no harmful substances, can be stored in a stand-by dry state for indefinite time period, is flexible and has tactile characteristics similar to that of textile. The main feature of this energy source is the separation of the electrolyte and the electrodes - the electrolyte is applied only when the battery needs to be activated. This makes storage time in a dry state virtually infinite. It expands their potential use to storage solutions and healthcare/health monitoring solutions, because the design of the battery allows it to be used as an active sensor, which generates electric current, when it detects liquid. We stress that this solution is suitable for specific applications only, outlined in the paper. The main components of the battery include aluminium anode, air cathode and the cotton shell. The design includes only textile-based materials, which ensure greater flexibility and better fusion with textile materials, where the battery is intended to be integrated. Besides that, results of the experiments with multi-cell battery prototype are presented.
\end{abstract}

Keywords Aluminium-air battery $\cdot$ Flexible battery $\cdot$ Smart textiles $\cdot$ Embroidery

\section{Introduction}

The alarm is intended for use by children during their sleep to treat enuresis. The prototype of the enuresis alarm system consisted of a shirt with detachable embroidered control circuit and power supply unit, as well as underpants with embroidered enuresis sensor. The idea of developing a flexible aluminium-air battery came from our previous research, which focussed on developing a textile enuresis alarm for children [1]. The power supply unit of the original system was based on Li-Ion battery and was integrated into the shirt. The system needs an integrated power supply, since it is

Miguel Carvalho

migcar@det.uminho.pt

Aleksandrs Vališevskis

aleksandrs.valisevskis@rtu.lv

Uǵis Briedis

ugis.briedis@rtu.lv

Fernando Ferreira

fnunes@det.uminho.pt

1 Institute of Design Technologies, Riga Technical University, Kīpsalas 6, Riga, Latvia

2 Textile Engineering Department, University of Minho, Campus de Azurem Guimaraes, Guimaraes, Portugal not feasible to use an external power supply in this setting. However, most commercially available chemical energy sources pose a certain degree of hazard due to their components-they either contain toxic materials or pose explosion risk if not wired/charged properly. One of the most promising alternatives was to use aluminium-air batteries, due to their costs, high theoretic energy density and non-toxicity [4, 7-9]. Besides that, since these batteries can be used with saline electrolyte, it is possible to use urine or other liquids for their activation. Such battery is activated right after the liquid is applied and reaches its maximum output as soon as it is sufficiently soaked. According to our experience, this takes just a few seconds. To be fully integratable into smart textiles, and/or wearable human/animal care products, these batteries must satisfy a number of requirements: materials should be non-toxic and safe, they should be flexible to ensure the comfort of the final wearable/textile product [1]. Another practical consideration was to make this cell modular, which means that cell design enables one to connect them in series to improve overall electrical performance.

It is known from experiments that the potential difference of aluminium-air batteries with saline electrolyte is approximately $0.7 \mathrm{~V}$. Thus, in order for the battery to power common semiconductor components without further conversion, 3 to 4 cells must be connected in series (which would 
increase the voltage 3 or fourfold). The size of the cells can be adapted to the necessary design of the product and application of the battery.

The current study described in this paper is based on our previous work. More specifically, the original flexible aluminium-air battery was a combination of metal meshes and textile materials [10]. This design was later improved by replacing pure metal meshes with metal-coated textile materials [11], which ensured better flexibility and eliminated problems with copper mesh oxidation.

This paper focuses on electrical properties and multi-cell design of such batteries.

\section{Batteries for smart textiles}

Smart textile field has been booming during the last decades and one of the main challenges that have been acknowledged was related to finding an energy source that is suitable for integration into wearables and particularly into smart textiles. Lately, a number of important studies have been published, which address just this problem. These studies focus on new materials and new approaches to powering smart textile; however, they will not be discussed here, since an extensive overview can be found in other papers $[2,3,5$, $6,11]$.

In this paper, we focus in particular on a new approach to the development of energy source for smart textiles that is based on the idea of electrolyte and electrode separation [11]. This approach has a number of advantages, such as indefinite storage time and the possibility to use this battery as a self-energised wetness sensor [10]. This enables to use the proposed design in medical applications, which often require a reaction to the appearance of bodily fluids. Examples include enuresis alarm systems, disposable bed mats, diapers for paediatric, elderly and stationary patients. Other applications include use in cold storage facilities and freezers, functioning as an electrochemical indicator, which changes its state in case of temperature rise. These applications are possible, because the batteries contain no toxic materials. Aqueous electrolyte is used for battery activation (should electrolytic properties of the liquid not be enough for battery successful activation, $\mathrm{NaCl}$ can be included into the inner layers of the dry battery (concentration 15\%), which dissolves and enhances the redox reaction). Electrolytic properties usually are ensured by dissolved ions.

The battery described in [11] is completely made from textile-based materials. Silver-coated permeable fabric is used as cathode current collector, which eliminates problems with oxidation, that the original copper current collector was prone to [10]. Besides that, its characteristics are comparable to that of the original battery, made using metal meshes.
The main objective of this study is the development of a multi-cell battery, which is based on the improved cell design [11]. A single-cell is a flexible element of arbitrary shape, usually square, with two electrodes-an anode and a cathode. By combining these cells in a particular way, it is possible either to increase voltage (by connecting cells in series) or to increase current (by connecting cells in parallel). It is intended to use the battery in a dry state. The electrolyte is added later and provokes activation of the system, which performs an operation. Thus, the following special considerations should be taken during the design of such a multi-cell battery: (1) cells must have an open design, so that the external electrolyte can reach all the cells; (2) at the same time, the cells must be sealed from one another, and (3) measures should be taken for directing electrolyte into individual cells and avoiding build-up of excessive electrolyte, which can make detrimental electric connections between cells.

\section{Components of the original al-air battery}

The original battery [10] consists of a copper mesh cathode with carbon granules, and an aluminium mesh anode. The single-cell battery has shown promising results (open-circuit voltage $V_{O C}=800 \mathrm{mV}$, short-circuit current $I_{S C}=50 \mathrm{~mA}$ ) [10]. Although the choice of the materials made the battery less flexible, so further studies have been conducted, which resulted in replacing all the metal meshes with alternative textile-based materials, without sacrificing the performance [11]. The improved design of single-cell flexible textile aluminium-air battery is shown and explicated in Fig. 1.

For aluminium anode Mtex ${ }^{\circledR}$ aluminium-textile composite fabric is used, which has textile base and textile-like tactile feel. Electric characteristics of this material are comparable to those of pure metal mesh. It is coated with aluminium, using thermal, binder-free coating process [12]. Since the outer layer is made of aluminium, it has all the necessary electrochemical characteristics for use in the battery.

Cathode current collector is made using Shieldex ${ }^{\circledR}$ Budapest, which is $99 \%$ pure silver-plated polyamide fabric and has surface resistivity $<1.0 \mathrm{Ohms} /$ [13]. Silver plating makes it particularly resistant to oxidation, which was an issue in the original design [10].

Outer shells are made of common cotton fabric, which ensures necessary tactile characteristics of the whole package.

Optional $\mathrm{NaCl}$ can be added to the air cathode. Its use and concentration should be evaluated based on the liquid, which is expected to activate the battery. Should its ion concentration not be enough to act as an electrolyte, $\mathrm{NaCl}$ should be added accordingly. 
Fig. 1 Flexible textile Al-Air battery cell. 1 -aluminium anode, Mtex ${ }^{\circledR}$ aluminium-textile composite material; 2 - cathode current collector, Shieldex ${ }^{\circledR}$ Budapest conductive textile; 3 - carbon granule and optional $\mathrm{NaCl}$ mixture to increase its concentration in electrolyte; 4 cotton enclosure of the cell; 5 cotton enclosure of the cathode; 6-sewn joints; 7-activating liquid from outer environment that is applied to the cell and that acts as an electrolyte

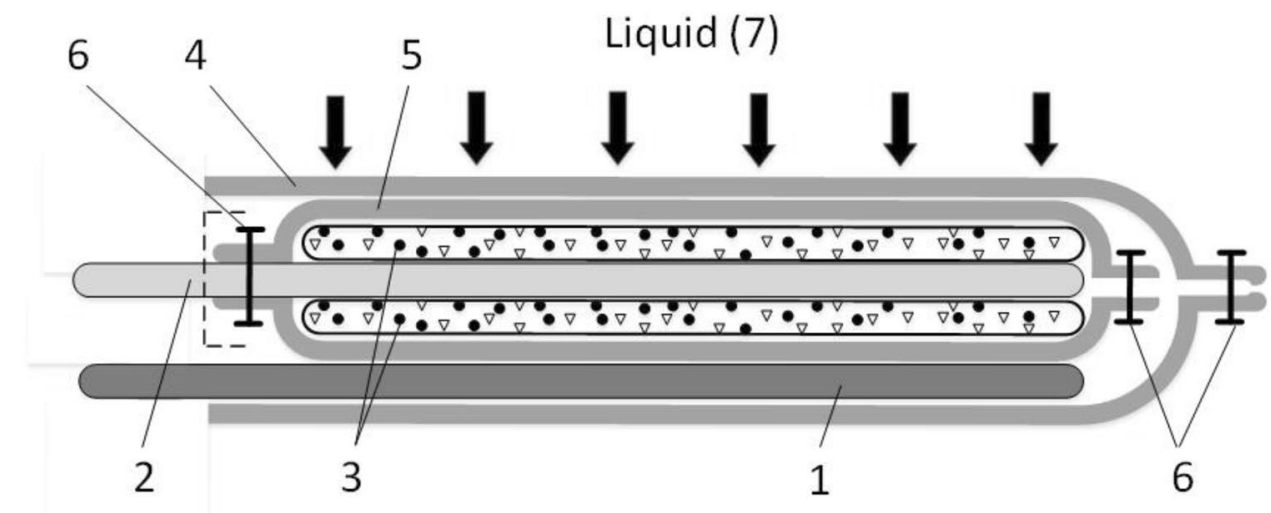

It was demonstrated that the newly chosen materials show promising results and their performance is equivalent to that of pure metal elements, which were used in the original design of the flexible Al-air battery and had caused various issues, mostly due to oxidation [11].

After suitable materials for flexible textile aluminiumair battery cells have been determined, it is now possible to focus on the design of multi-cell battery and the arrangement of individual cells.

The modular design of the battery enables one to choose an arbitrary number of cells and their arrangement on the plane. Since one cell of the chosen type produces about $0.7 \mathrm{~V}$, it was decided to prepare a battery with 4 cells, connected in series. This arrangement should quadruple the potential and gives an output voltage of about $2.8 \mathrm{~V}$, which is enough for most low-power semiconductor electronics and sensors. In this case, maximum current remains unchanged-should the application require to increase the current and not the voltage, the cells should be arranged in parallel. In the described battery, the cells are arranged linearly, because it was intended for use in a wristband prototype.

\section{Multi-cell battery design}

Previous studies [11] show that better results are obtained when individual cells are arranged on a plane, rather than stacked on top of each other. This is because such an arrangement ensures a better electrical insulation of the cells. Thus, the biggest challenges in combining flexible textile cells on a textile substrate is to ensure their insulation by directing the flow of electrolyte and making connections in an appropriate way. This can be achieved by proper insulation of the individual cells with appropriate sealants. Cells are arranged on a plane. Their stacking on top of each other does not allow to ensure a proper insulation and flow of electrolyte at the same time, which decreases performance of the battery.

The designed battery prototype (see Fig. 2) presents four cells connected in series. The cells are arranged on a plane and are adjacent to each other in a way that the cathode of one cell overlays the anode of the next cell, etc. Since the materials are textile-based, the connection is made by sewing the electrodes together with conductive thread. The cells are incapsulated into two layers of non-permeable fabric, using commercially available seam sealer. The lower layer is made of solid rectangular piece of fabric and the upper layer is made of the same fabric with four openings that allow electrolyte to reach the cells. The sealant is applied on the cathode/anode connection area and around the cells, to insulate them. The fabric has hydrophobic coating, which

Liquid

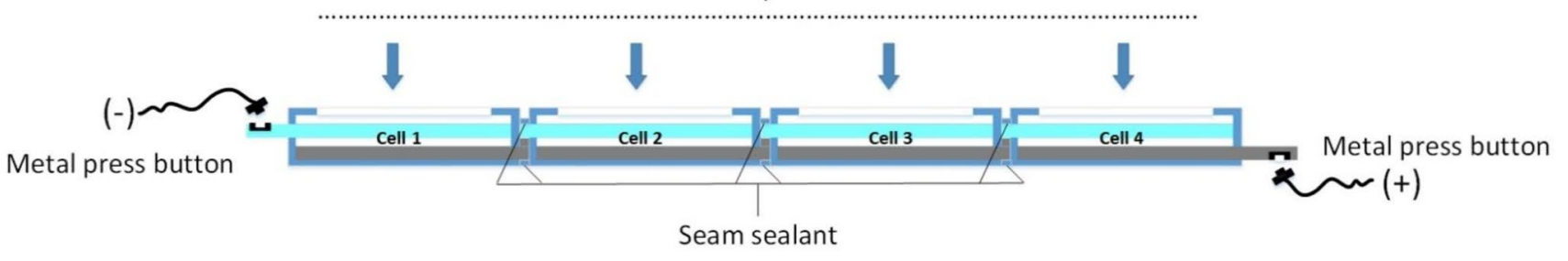

Fig. 2 Multi-cell battery design, side view 
minimises electrolyte accumulation on the upper layer of the battery and detrimental connection bridges, as well as it enables the electrolyte to be distributed among the cells. The only non-insulated electrodes are the anode of the first cell and the cathode of the last cell, which are the poles of the multi-cell battery.

To test the actual characteristics of the newly designed battery, a multi-cell (4 cells) flexible textile aluminiumair battery prototype was developed (see Fig. 3), which consists of four sealed cells. The battery can produce $3 \mathrm{~V}$ upon activation, which enables it to power semiconductors without the need of additional voltage conversion or energy accumulation.

The basic characteristics of the battery are discussed in the next section.

\section{Results and discussion}

The current-voltage curve of a 4-cell battery is presented in Fig. 4. As can be seen, it produces open-circuit voltage (OCV) of almost $3 \mathrm{~V}$ and has short-circuit current of almost
$60 \mathrm{~mA}$. Due to the intended application of the battery, OCV change over time was not measured. However it was observed that upon introduction of the electrolyte aluminium anode starts to deteriorate and should not be expected to last for more than a few days, even without load.

To be consistent with our previous experiments [11], the capacity of the battery was measured by putting it under a constant $22 \Omega$ load. As was stated before, this particular battery design is not intended for long-time storage in the active state-it is used to perform a particular task upon activation and should be reset afterwards. Voltage/current change over time under load can be seen in Figs. 5 and 6.

As can be seen from Fig. 5, voltage drops to around $50 \mathrm{~mA} 120 \mathrm{~min}$ after activation under a load of $22 \Omega$. Current change over time is shown in Fig. 6, after $120 \mathrm{~min}$ it drops to around $2 \mathrm{~mA}$. These figures show that it is practically possible to use the battery for powering demanding semiconductor electronics, such as wireless transmitters and sensors for a limited time of a few hours, depending on the actual load.

Only one cycle was performed during the experiments due to a number of factors: (1) this particular design of the primary battery is not intended for repetitive use, but

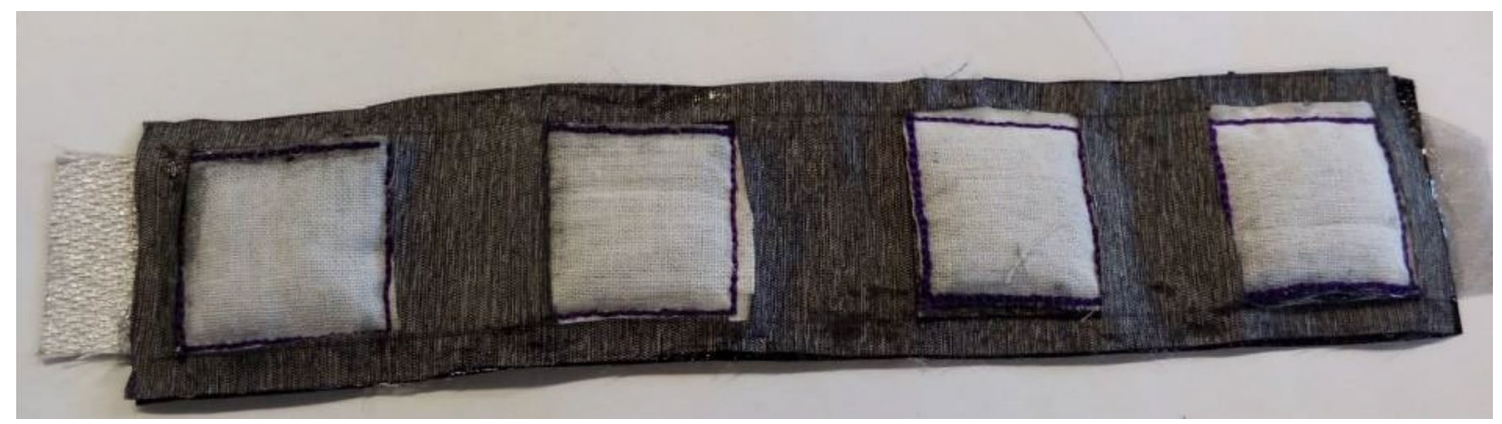

Fig. 3 Prototype of a multi-cell flexible textile Al-Air battery with cells arranged on a plane

Fig. 4 Current-Voltage characteristic of a 4-cell battery

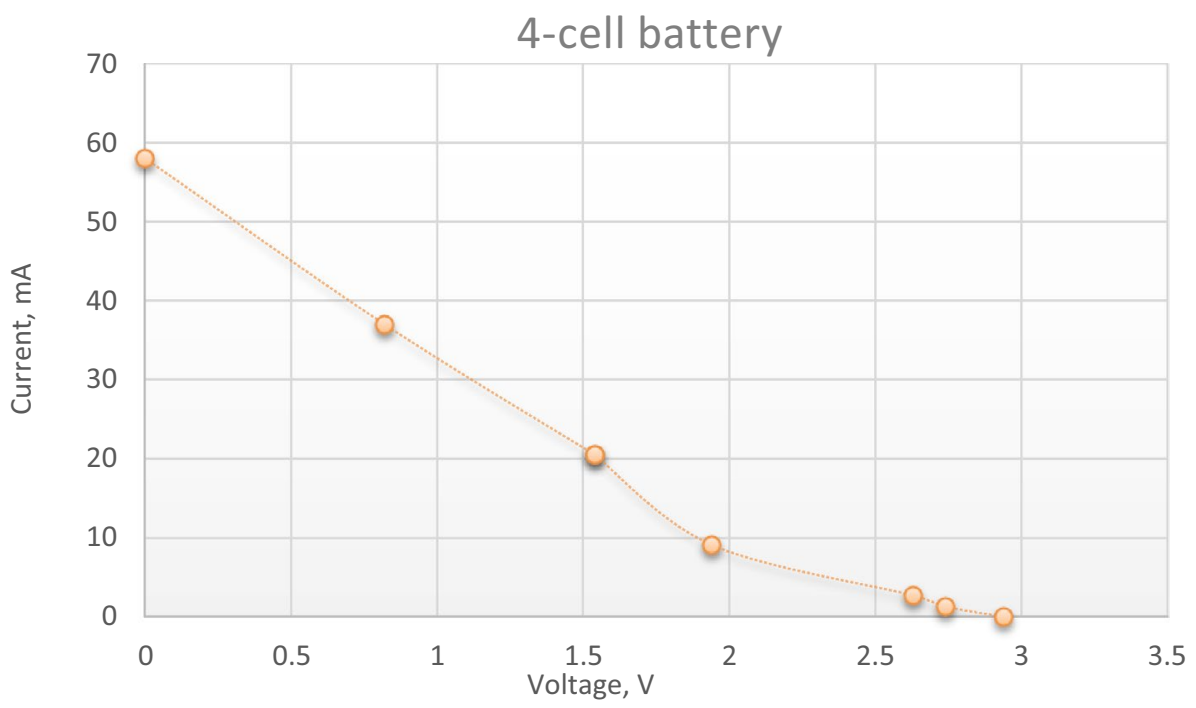


Fig. 5 Voltage change over time of a 4-cell battery with $22 \Omega$ load applied

\section{Voltage over time with $22 \Omega$ load}

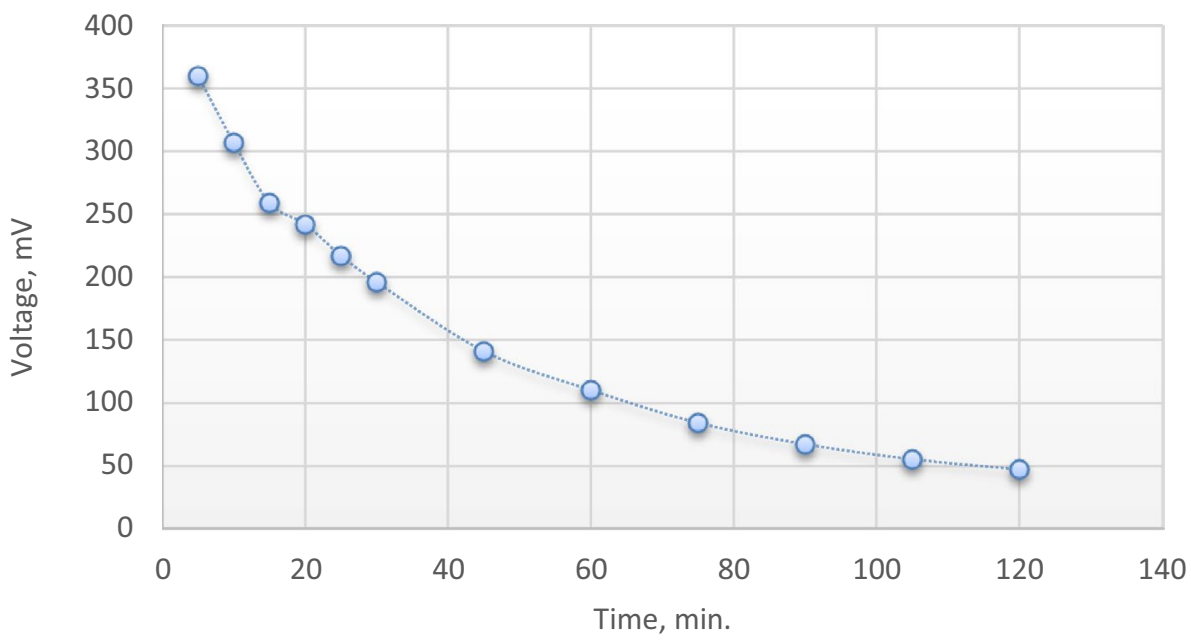

Current over time with $22 \Omega$ load

of a flexible textile battery with $22 \Omega$ load applied

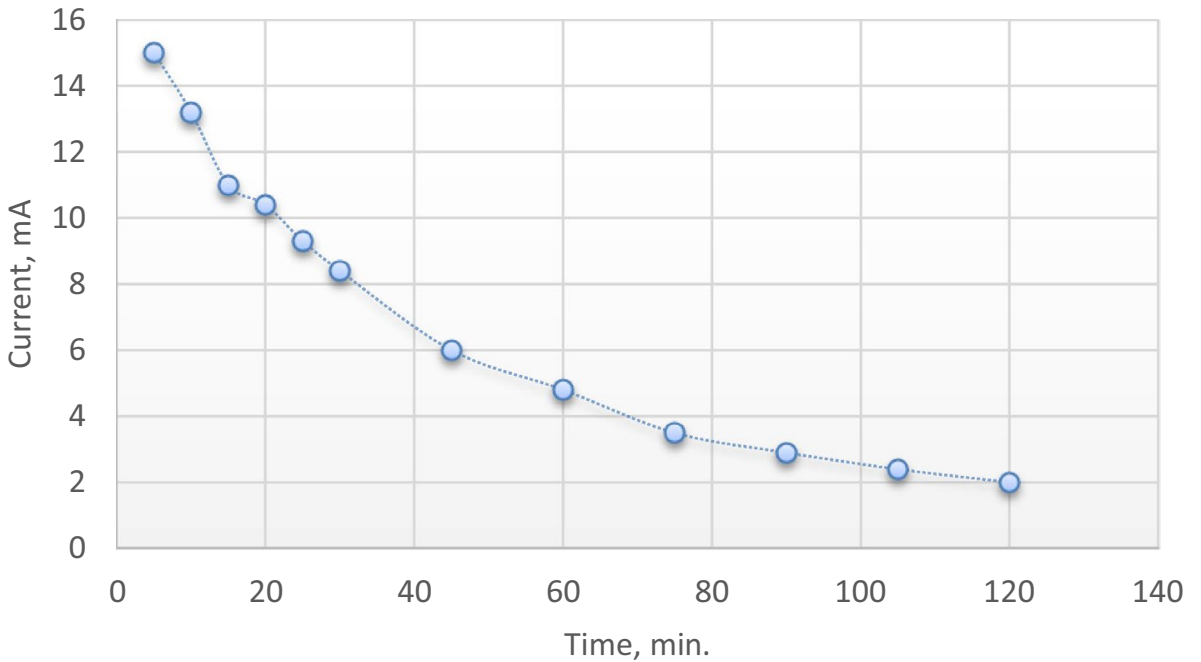

rather for one-time activation to change the state of the system, (2) aluminium anode oxidises and deteriorates quickly in the presence of electrolyte, (3) thus, to reactivate the battery for next cycles, physical replacement of the aluminium anode is necessary, which, after drying of the remaining components, should return its electrical characteristics to the original level.

This completes an important step on the path to developing a functional multi-cell energy source that can be used in wide variety of applications.

The focus of further studies will be on construction improvements, practical usability and further study of cell deterioration under various loads.

\section{Conclusion}

This paper presents a further development of an aluminium-air battery that was proposed in [10] and improved in [11]. The paper shows how individual cells can be combined to obtain higher electrical characteristics, which are enough to power common semiconductor electronics. Charts are presented, which show the operational characteristics of such batteries.

Due to oxidation of aluminium anode, this kind of batteries are not intended for long-term storage in activated state. However, they can be integrated into the final 
product and remain in inactive state without electrolyte for virtually unlimited time, which expands their potential use to storage solutions and various healthcare products.

Acknowledgements This work has been supported by the European Regional Development Fund within the project no. 1.1.1.1/16/A/020 "Synthesis of textile surface coating modified in nano-level and energetically independent measurement system integration in smart clothing with functions of medical monitoring".

Open Access This article is licensed under a Creative Commons Attribution 4.0 International License, which permits use, sharing, adaptation, distribution and reproduction in any medium or format, as long as you give appropriate credit to the original author(s) and the source, provide a link to the Creative Commons licence, and indicate if changes were made. The images or other third party material in this article are included in the article's Creative Commons licence, unless indicated otherwise in a credit line to the material. If material is not included in the article's Creative Commons licence and your intended use is not permitted by statutory regulation or exceeds the permitted use, you will need to obtain permission directly from the copyright holder. To view a copy of this licence, visit http://creativecommons.org/licenses/by/4.0/.

\section{References}

1. Briedis, U., Vališevskis, A., Grecka, M.: Development of a smart garment prototype with enuresis alarm using an embroiderymachine-based technique for the integration of electronic components. Procedia. Comput. Sci. 104, 369-374 (2016). https://doi. org/10.1016/j.procs.2017.01.147. (ISSN 1877-0509)

2. Jost, K., Dion, K., Gogotsi, Y.: Textile energy storage in perspective. J. Mater. Chem. A2, 10776-10787 (2014)

3. Jost, K., Pérez, C., Mcdonough, J., Presser, V., Heon, M., Dion, G., Gogotsi, Y.: Carbon coated textiles for flexible energy storage. Energy. Environ. Sci. 4, 5060-5067 (2011). https://doi. org/10.1039/C1EE02421C

4. Avoundjian, A., Galvan, V., Gomez, F.A.: An inexpensive paperbased aluminum-air battery. Micromachines 8, 222 (2017)
5. Normann, M., Kyosev, Y., Ehrmann, A., Schwarz-Pfeiffer, A.: Multilayer textile-based woven batteries. In: Kyosev, Y. (ed.) Recent developments in braiding and narrow weaving. Springer, Cham (2016). https://doi.org/10.1007/978-3-319-29932-7_13

6. Resuli, R., Turhan, I., Ehrmann, A., Blachowicz, T.: Textile-based batteries with nanofiber interlayer. AIMS. Energy. (2018). https:// doi.org/10.3934/energy.2018.2.261

7. Li, Q., Bjerrum, N.J.: Aluminum as anode for energy storage and conversion: a review. J. Power. Sour. 110(2), 1-10 (2002). (ISSN: 03787753)

8. Yang, S., Knickle, H.: Design and analysis of aluminum/air battery system for electric vehicles. J. Power. Sour. 112(1), 162-173 (2002). (ISSN: 03787753)

9. Liu, Y., Sun, Q., Li, W., Adair, K.R., Li, J., Sun, X.: A comprehensive review on recent progress in aluminum-air batteries. Green Energy Env 2(3), 246-277 (2017). https://doi.org/10.1016/j. gee.2017.06.006. (ISSN 2468-0257)

10. Briedis, U., Vališevskis, A., Zelča, Z.: Flexible aluminium-air battery for enuresis alarm system. In: 16th international scientific conference "engineering for rural development": Proceedings. Latvia, Jelgava, Jelgava (16) 619-624. ISSN 1691-3043. Available from: doi:https://doi.org/10.22616/ERDev2017.16.N123 (2017)

11. Vališevskis, A., Briedis, U., Juchnevičiene, Ž, Juciene, M., Carvalho, M.: Design improvement of flexible textile aluminium-air battery. J Text Inst 12, 1-6 (2019). https://doi.org/10.1080/00405 000.2019.1676521. (ISSN 0040-5000. e-ISSN 1754-2340)

12. Frenzelit GmbH. Mtex Metal-textile compound materials, brochure. Frenzelit GmbH. BE1/03.03/02/BE (2017)

13. Statex Productions- und Vertriebs GmbH. Shieldex Budapest No. 1101701, technical data sheet. Statex Productions- und Vertriebs GmbH. 25.04.13/03 (2013)

Publisher's Note Springer Nature remains neutral with regard to jurisdictional claims in published maps and institutional affiliations. 